\title{
A25 NEW AUTOANTIBODIES ASSOCIATED WITH EARLY RHEUMATOID ARTHRITIS
}

Charpin $\mathrm{C}_{1}^{1,2}$ Martin $\mathrm{M}_{1}{ }^{1}$ Balandraud $\mathrm{N}_{1}^{1,2}$ Toussirot $\mathrm{E}_{1}^{3}$ Wendling $\mathrm{D},{ }^{3}$ Roudier $\mathrm{J}_{1}^{1,2}$ Auger I 11 INSERM UMR 639, Immunogénétique de la polyarthrite rhumatoïde, Marseille, France; ${ }^{2}$ Assistance Publique des Hôpitaux de Marseille, Marseille, France; ${ }^{3}$ Service de Rhumatologie, Hôpital Jean Minjoz, Besançon, France

\subsection{6/ard.2010.149096.25}

Background and objectives Rheumatoid arthritis (RA) is an autoantibody mediated disease. Among the various autoantibodies known in RA, autoantibodies to citrullinated proteins (ACPA) are highly specific. ACPAs are detected by an ELISA using synthetic cyclic citrullinated peptides (anti-CCP). AntiCCP antibodies identify $60 \%$ of RA patients. A negative result in anti-CCP antibody testing does not exclude RA. Therefore, there is a great need for new biological markers. By using arrays containing 8000 human proteins, we have identified 24 'new autoantigens' associated with RA patients with disease duration less than 1 year. These results were obtained with the sera of 20 RA patients with disease duration less than 1 year versus 23 controls.

Materials and methods To confirm these reactivities, we tested by ELISA the sera of extra RA patients and controls on these 24 'new autoantigens'. We tested 47 RA patients with disease duration less than 1 year and 25 RA patients with disease duration between 5 and 20 years. We also tested 66 patients with ankylosing spondylitis (AS), 21 patients with psoriasis arthritis (PsA) and 38 healthy subjects.

Results Among the 24 proteins associated with early RA patients, we have identified 9 proteins (P1-P9) that are preferentially recognised by autoantibodies from early RA patients. Indeed, these proteins are recognised by $25-47 \%$ of RA patients with disease duration less than 1 year and less than $5 \%$ of controls. Of interest, autoantibodies to P1 are very specific for early RA. Indeed, $47 \%$ of RA patients' sera recognise $\mathrm{P} 1$ versus $0 \%$ of AS patients $\left(\mathrm{p}<10^{-7}\right), 0 \%$ of PsA patients $(\mathrm{p}=0.0001)$ and $0 \%$ of healthy individuals $\left(\mathrm{p}<10^{-5}\right)$.

Conclusions We have identified 9 proteins which are recognised by the sera of patients with early RA. These proteins could potentially be used as diagnosis markers in RA patients. 